\title{
Ferritik Çeliklerde Kırılma Tokluğunun Saptanmasında Farklı Bir Yaklaşım
}

\section{A Different Approach to the Determination of the Fracture Toughness in Ferritic Steels}

\author{
Halil AYTEKİN*1,a, Yelda Akçin ERGÜN ${ }^{1, b}$, Melih ÖZÇATAL 1,c \\ IAfyon Kocatepe Üniversitesi, Teknoloji Fakültesi, Metalurji ve Malzeme Mühendisliği Bölümü, 03200, Afyonkarahisar
}

• Geliş tarihi / Received: 15.03.2020 • • Düzeltilerek geliş tarihi / Received in revised form: 01.07.2020 • Kabul tarihi / Accepted: 10.07 .2020

$\ddot{O} \mathbf{z}$

Günümüzde, malzeme seçimi, geleneksel olarak malzemenin akma dayanımına göre yapılmaktadır. Ancak burada, parça dizaynı veya geometrik unsurlardan kaynaklanan gerilim konsantrasyonları dikkate alınmamaktadır. Bu şartların değerlendirilmesi, sadece malzemenin kırılma tokluğu ile mümkündür. Kırılma tokluğunun saptanmasında, metalik malzemeler için, ASTM E-399 standardı geliştirilmiştir. Bu standart uyarınca, düzlemsel deformasyon durumuna (gevrek kırılma) uygun olarak hazırlanmış olan numuneler test edilir. Özellikle ferritik çeliklerde, bu durum büyük boyutlu numuneler üzerinde deney yapılmasını gerektirir ve böylece söz konusu çeliklerin kırılma tokluğunun saptanması zorlaşır. Bununla birlikte, bazı alternatif yöntemler geliştirilmiş̧ir. Başlıca yöntemler, J-İntegral ve COD yöntemleridir. J-İntegral yönteminin yüksek toleransının sınır şartlarını belirlemek için ASTM E-1921 standardı geliştirilmiş ve Master Curve (MC) kavramı ortaya atılmıştır. Bu yöntemlerin olumsuz yanı, oldukça yüksek tolerans göstermesidir. Bu çalışmada, kırılma tokluğunun saptanmasında yeni bir yöntem incelenmiş ve literatürde yapılmış çalışmalar derlenerek, yeni bir yaklaşım ile yöntemin geliştirilmesi amaçlanmıştır.

Anahtar kelimeler: Akma Dayanımı, ASTM E1921 Standardı, ASTM E399 Standardı, Kırılma Tokluğu

\begin{abstract}
Nowadays, the material selection is conventionally made according to the yield strength of the material. However, stress concentrations from geometric factors or component design are not considered. The evaluation of these conditions is only possible with fracture toughness of the materials. ASTM E-399 has been developed for the determination of fracture toughness of the metallic materials. According to this standard, samples suitable to the plane deformation (brittle fracture) are tested. Especially in ferritic steels, this condition requires testing on large-sized samples, and thus, it is difficult to determine the fracture toughness of these steels. However, some alternative methods have been developed into this standard. The major methods are J-integral and COD methods. ASTM E-1921 standard was developed in order to determine the boundary conditions of the high tolerance of J-integral method, and Master Curve (MC) concept was proposed. The disadvantage of these methods is that they show quite high tolerance. In this study, a new method has been investigated in the determination of the fracture toughness. The similar studies in the literature have been compiled, and developing of the method with a new approach was purposed.
\end{abstract}

Keywords: Yield Strength, ASTM E1921 Standards, ASTM E399 Standards, Fracture Toughness

\footnotetext{
*a Halil AYTEKIN; aytekinhll@gmail.com, Tel: (0272) 21825 02, orcid.org/0000-0003-3281-3703

${ }^{\mathrm{b}}$ orcid.org/0000-0003-3474-8722 $\quad{ }^{\mathrm{c}}$ orcid.org/0000-0002-0831-9038
} 


\section{Giriş}

Günümüzde, malzeme seçimi, geleneksel olarak malzemenin akma dayanımına göre yapılmaktadır. Ancak, akma dayanımına göre yapılan malzeme seçiminde, parça dizaynı veya parçanın geometrik yapısından kaynaklanan gerilim konsantrasyonları dikkate alınmamaktadır. $\mathrm{Bu}$ durumların değerlendirilmesi, sadece malzemenin kırılma tokluğu ile mümkündür. Metalik malzemelerin kırılma tokluğunun $\left(K_{I C}\right)$ saptanmasinda, ASTM E-399 standard1 geliştirilmiştir (ASTM E399-17, 2017). Bu standarda göre, düzlemsel deformasyon durumuna (gevrek kırılma şartı) uygun numuneler üzerinde deney yapılmalıdır. Özellikle ferritik çeliklerde (HMK kafes yapısına sahip çelikler), numunede gevrek kırılma şartının sağlanması için büyük boyutlu numuneler üzerinde deney yapılmas1 gerekir ve bu nedenle söz konusu çeliklerin kırılma tokluğunun saptanması zorlaşır. Bununla birlikte, bazı alternatif yöntemler geliştirilmiştir. Başlıca yöntemler, J-İntegral (Gdoutos, 1993; Rice, 1964) ve COD (Çatlak Açılma Deplasmanı) (Burdekin ve Stone, 1966; Gdoutos, 1993) yöntemleridir. J-İntegral yönteminin yüksek toleransının sınır şartlarını belirlemek için ASTM E-1921 (ASTM E1921-18, 2018) standard1 geliştirilmiş ve Master Curve (MC) kavramı ortaya atılmıştır.

Ferritik çelikler için geliştirilen ASTM E1921 standardına göre, kırılma mekaniği test pratikleri ve ileri istatistiksel metotlar kullanılarak, akma gerilimi 275-825 $\mathrm{MPa}$ arasında olan ferritik çeliklerin kırılma tokluğunun sünek - gevrek geçiş aralığ1 saptanmaktadır. $\mathrm{Bu}$ standarda göre malzemeler, makroskobik ölçüde düzgün dağılımlı (homojen) mekanik özelliklere (çekme ve tokluk) sahip olmalıdır (ASTM E1921-18, 2018). Bu standartta, numune üzerinde lineer elastik durum (gevrek kırılma şartı) sağlanması gerekmez. Bununla birlikte, kırılma tokluğuna numune boyutunun etkisi, en zayıf bağ (weakestlink) mekanizması, yani kırılma bölgesindeki çatlak başlatıcılar (çökeltiler, inklüzyonlar ve tane sınırı gevrekliği gibi çelikteki tüm mikro yapısal özellikler) ile açıklanır (McCabe vd., 2000).

Ferritik çeliklerin kırılma tokluğuna yükleme hızının etkisinin araştırıldığı bir çalışmada, referans sıcaklığının saptanmasında kullanılan denklemin, yüksek yükleme hızlarında bir belirsizliğe yol açtığı, bu durumun telafisi için eğri uydurma parametrelerinin yeniden düzenlenmesi gerektiği ortaya konmuştur (H.-J. Schindler ve Kalkhof, 2015).
Bir çalışmada, çekme testi sonuçlarının sonlu elemanlar analizi yapılarak, Master Curve'in tek sıcaklık yöntemi ile basınç kaplarının yapısal bütünlügünün değerlendirmesinde önemli bir rol oynayan kırılma tokluğu parametresi yüksek doğrulukta tahmin edilmiştir (Pan vd., 2019). Kırılma tokluğunun geçiş ve üst limit eğrilerinin araştırıldığı bir çalışmada, fizik temelli ve kantitatif bir model geliştirmek için bir metodoloji geliştirilmiştir. $\mathrm{Bu}$ çalışmada, kırılma tokluğunun sıcaklığa bağl1lığının, akma dayanımının sıcaklığa bağl11ı̆̆ 1 ile aynı forma sahip olduğunu gösterilmiştir (EricksonKirk ve EricksonKirk, 2006). Süneklikten gevrekliğe geçiş bölgesinde ferritik çeliklerin kırılma direncinin karakterizasyonu, boyut ve sicaklik bağımlılıklarının yanı sıra, sonuçlardaki dağılım nedeniyle sorunludur. Bu Master Curve konsepti, büyük bir teknolojik avantaj olmasına rağmen, daha derin bir analize ihtiyaç duyan birçok yönü vardır. Bunlar; 1) $\mathrm{J}$ veya $\mathrm{K}$ sonuçları kullanıldığında Weibull şekil parametreleri arasındaki ilişki, 2) ASTM standardında uygulanan numune boyutları dönüşümünün boyut etkisi ve geçerliliği, 3) bir kısıtlamanın hesaba katılmadan sadece istatistiksel etkiye dayalı bir modelin geçerliliğidir (Berejnoi ve Ipiña, 2016).

Bir mühendislik güvenlik analizi için, KIC'nin deterministik alt sınırları genellikle Master Curve yaklaşımına dayanan istatistiksel $\mathrm{K}_{\mathrm{IC}}$ verilerinden daha uygundur. Bununla birlikte, sünek ile gevrek sıcaklık aralığındaki ferritik çelikler için $\mathrm{K}_{\mathrm{IC}}$ değerleri doğrudan ölçülemez, yani ASTM E399 standardı onlar için uygulanabilir değildir (H.J. Schindler, 2014). ASTM E1921 standardında veri kümesi boyutunun, küçük veri kümelerinin büyük belirsizliklere yol açtığı düşünüldüğünde, bir Weibull grafiğgi eğiminin değişkenliği üzerinde güçlü bir etkisi vardır. Yapı çeliklerinin kırılma tokluğundaki değişkenliğin araştırıldığı bu çalışmada, yeni bir modelle saptanan Weibull eğiminin, kırılma olasılığına katkıda bulunan (sadece çatlak düzlemine yakın olan) unsurlar kullanılarak açıklanması daha uygundur (Bouchard vd., 2008).

Master Curve (MC) kırılma modelinde, reaktör basınç kabı (RPV) uygulamalarında kullanılanlar da dahil olmak üzere, ferritik çelikler için evrensel bir sıcaklık bağımlılığı varsayılmaktadır. Varsayılan eğri şeklinin, yüksek bir referans geçiş sıcaklığı değeri sergileyen yüksek ışınlanmış veya termal olarak yaşlanmış malzemeler için de genel olarak geçerli olduğu gözlemlenmiştir. Kırılma olayı, geçiş eğrisinin şeklinde hafif bir sapma yapabilir. Geçiş eğrisi şeklini ve 1şınlamaya bağlı 
olası değişikliklerini analiz etmek için uygun veri seti istatistiksel olarak yeterince büyük olmalıdır (Planman vd., 2008). Reaktör basınç kabının (RPV) bütünlügü, bir nükleer santralin (NPP) sürekli çalışması için gereklidir. Nükleer santrallerde reaktör basınç kaplarının kırılma tokluğunu izlemek için Master Curve yaklaşımının incelendiği bu çalışmada, ASTM E1921'de verilen sabit C parametresi varsayımının, orta derecede kırılma tokluğu sergileyen ışınlanmış çoğu malzeme için iyi bir yaklaşım sağladığı görülmüştür (IAEA, 2009).

$\mathrm{Bu}$ çalışmada, ferritik çeliklerin kırılma tokluğunun belirlenmesinde, uygulanması kolay, malzemenin geleneksel mekanik özelliklerini dikkate alan ve malzemenin kırılma tokluğunun doğasını açıklayan bir yöntem kullanılmıştır. $\mathrm{Bu}$ yöntemin en büyük avantaj1, kırılma tokluğunun geleneksel mekanik özellikler ile ilişkisi temelinde, yeni yaklaşımlara açık olmasıdır. Ayrıca, kırılma tokluğunun hangi mekanik özelliklere, ne şekilde bağlı olduğunun ortaya konmasına yardımcı olmaktadır. Böylece, malzemenin kırılma tokluğunun geliştirilmesine olanak sağlamaktadır (Aytekin, 2005, 2009, 2014; Said, 2006; Said ve Aytekin, 2013; Said ve Tasgetiren, 2004; Said ve Taşgetiren, 2000; Saidov, 1997; Sa1d ve Talas, 2004; Ulu vd.,
2013). Bu çalışmanın amacı, ferritik çeliklerin kırılma tokluğunun belirlenmesinde, söz konusu yöntem temelinde yeni bir yaklaşım geliştirmektir. Geliştirilen yaklaşımda, sadece oda sıcaklığında yapılan çekme testi sonuçları kullanılarak kırılma tokluğu saptanabilmektedir. Ayrıca, bu yaklaşım, ASTM E399 standard1 test verileri ile de karşılaştırılmıştır. Bunun için, Aytekin'in çalışmasından (Aytekin, 2009) alınan deneysel veriler kullanılmışırır. Sonuçta, ilgili yaklaşımın güvenilirliği ortaya konmuş ve yeni yaklaşımın ferritik çeliklerin kırılma tokluğunun saptanmasında önerilmesi amaçlanmıştır.

\section{Materyal ve Metot}

\subsection{Malzeme}

Çalışma kapsamında yapılan tüm araştırmalar, beş farklı ferritik çelik üzerinde yapılmıştır. Bu çeliklere ait veriler, Aytekin'in çalışmasından alınmıştır (Aytekin, 2009).

$\mathrm{Bu}$ çalışmada, incelenen çeliklerin kimyasal bileşimleri, Tablo 1'de verilmiştir. Bu çelikler, genellikle nükleer enerji santralinin reaktör gövdeleri, petrol ve gaz ana boru hatlarında ve yüksek basınç kapları yapımında kullanılır (Aytekin, 2009).

Tablo 1. İncelenen çeliklerin kimyasal bileşimleri (Aytekin, 2009).

\begin{tabular}{cccccccccc}
\hline \multirow{2}{*}{ Çelik No } & $\mathbf{C}$ & $\mathbf{S i}$ & $\mathbf{M n}$ & $\mathbf{S}$ & $\mathbf{C r}$ & $\mathbf{N i}$ & $\mathbf{C u}$ & $\mathbf{M o}$ & $\mathbf{V}$ \\
\cline { 2 - 10 } & & & & & $\%$ & & & & \\
\hline 1 & 0.16 & 0.28 & 0.53 & 0.008 & 2.23 & 1.34 & 0.12 & 0.54 & 0.11 \\
2 & 0.11 & 0.22 & 0.90 & 0.0016 & 0.22 & 1.92 & 0.21 & 0.55 & 0.04 \\
3 & 0.15 & 0.25 & 0.68 & 0.01 & 1.22 & 0.29 & 0.02 & 0.97 & 0.31 \\
4 & 0.11 & 0.56 & 1.37 & 0.023 & 0.17 & 0.22 & 0.20 & - & - \\
5 & 0.084 & 0.23 & 1.68 & 0.007 & 0.023 & 0.02 & 0.013 & 0.044 & 0.064 \\
\hline
\end{tabular}

Tablo 1'e bakıldığında, incelenen çeliklerin düşük karbonlu çelik olduğu görülmektedir. Bu durum, tipik olarak ferritik çeliğe işaret etmektedir.

\subsection{ASTM E399 Standardı}

Metalik malzemelerin lineer elastik düzlemsel deformasyon kırılma tokluğunun $\left(K_{I C}\right)$ saptanmasinda, ASTM E399 standard1 geliştirilmiştir. Bu standarda göre, lineer elastik kırılma durumunun (düzlemsel deformasyon durumu) sağlanabilmesi için test numunesinde gevrek kırılma şartı sağlanmalıdır. Yani, test numunesinin belirli bir kalınlığa sahip olması gerekir. Özellikle düşük akma gerilimine sahip ferritik çeliklerin kırılma tokluğunun saptanabilmesi için, düzlemsel deformasyon (hacimsel gerilme) durumuna uygun büyük boyutlu numuneler deneye yapılmalidır (ASTM E399-17, 2017).

ASTM E-399 standardına göre kırılma tokluğunun belirlenmesinde kullanılan en genel numune tipi, kompakt çekme (Compact Tension $\mathrm{CT})$ numunesidir. $\mathrm{Bu}$ numunenin, kalınlığa $(t)$ bağlı tüm ölçüleri ve şematik gösterimi Şekil 1'de verilmiştir (ASTM E399-17, 2017). 


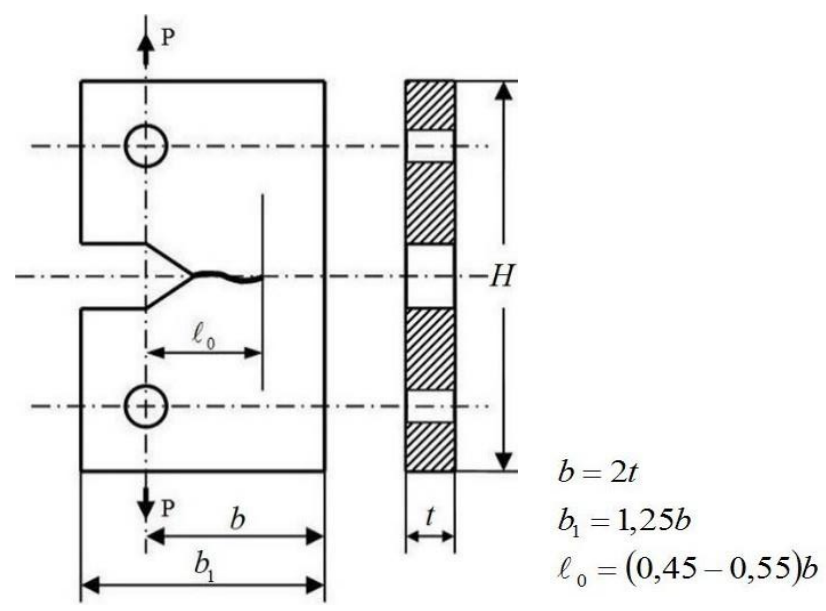

Şekil 1. Kompakt çekme (CT) numunesinin şematik gösterimi
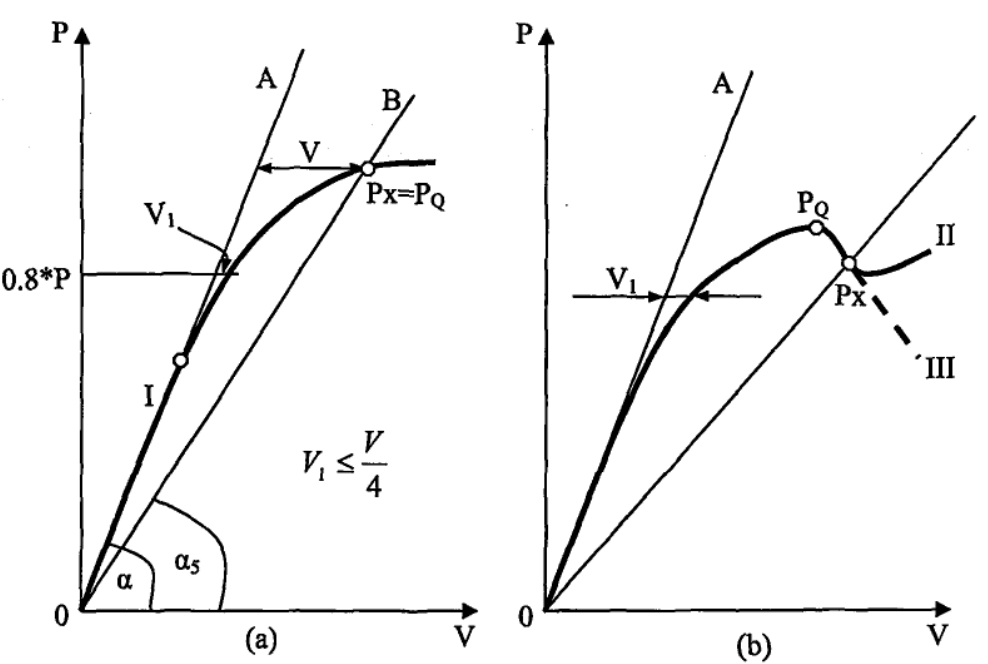

Şekil 2. Kuvvet - çatlak açılma $(P-V)$ grafiği

Şekil 2'ye bakıldığında, genel olarak 3 tip eğri görülmektedir. Şekil 2, a'da I. tip eğri için elastik bölge çizgisinden $\% 5$ daha küçük bir açıda $\mathrm{OB}$ çizgisi çekildiğinde, eğriyi kesen nokta $P_{Q}$ kuvveti olarak adlandırılır. Şekil 2 b'de ise II. ve III. tip eğriler için $P_{Q}$ kuvveti şekil üzerinde gösterildiği gibidir (ASTM E399-17, 2017).

Grafik analizinden sonra $K_{Q}$ parametresi hesaplanır. Bu parametrenin farklı numune tipleri için (genel olarak 4 tip numune kullanılır) denklemleri olsa da, kompakt çekme (CT) numunesi için gerekli denklem aşağıda verilmiştir (ASTM E399-17, 2017).

$K_{Q}=\left(\frac{P_{Q}}{t \sqrt{b}}\right) Y$

$Y=13.74\left[1-3.38\left(\frac{\ell_{0}}{b}\right)+5,572\left(\frac{\ell_{0}}{b}\right)^{2}\right]$
ASTM E-399 standardına göre, Şekil 1'de verilmiş olan numuneye (CT1T - 1 inç'lik kompakt çekme) ilk önce çentik açılır, daha sonra yorulma cihazı yardımıyla bu çentik ucundan başlayan ve belirli bir uzunluğa sahip çatlak oluşturulur. Deney sonrasında gerçek çatlak uzunluğu numune üzerinden ölçülmelidir. Daha sonra, bu ön çatlaklı numuneler, çekme deneyine tabi tutulur ve bu deneyden kuvvet - çatlak açılma $(P-V)$ grafikleri elde edilir. Elde edilen grafiklerdeki eğriler, aşağıdaki gibi değerlendirilmelidir (ASTM E399-17, 2017).

(b)

Numune boyutları ile çatlağın yerleşimini göz önünde bulunduran $Y$ parametresi, bir düzeltme parametresidir.

Denklem 1'e göre kırılma tokluğunun değerlendirilebilmesi için, numunede gevrek kırılma şartı araştırılmalıdır. Şekil 3'te numune kalınlığ 1 ile kırılma tokluğu arasındaki ilişki verilmiştir. Gevrek kırılma şartının sağlanması için numunenin belirli bir kalınlıkta olması şarttır (Broek, 1982).

Şekil 3'e bakıldığında, numune kalınlığının artmasına bağlı olarak $K_{C}=K_{Q}$ değeri azalırken, belirli bir numune kalınlığından sonra değişmemektedir. $\mathrm{Bu}$ kalınlıkta $K_{C}=K_{I C}$ olmaktadır. Numune kalınlığı artsa da $K_{I C}$ değeri değişmez. Bu sebeple, $K_{I C}$ malzeme sabiti sayılır. Bununla birlikte, kırılma türü sünek kırılmadan $\left(K_{C(\max )}\right)$, gevrek kırılmaya $\left(K_{I C}\right)$ doğru değişmektedir. Numune kalınlığı ile kırılma 
tokluğu $\left(K_{I C}\right)$ arasındaki ilişki, aşağıdaki denklemde verilmiştir (Broek, 1982).

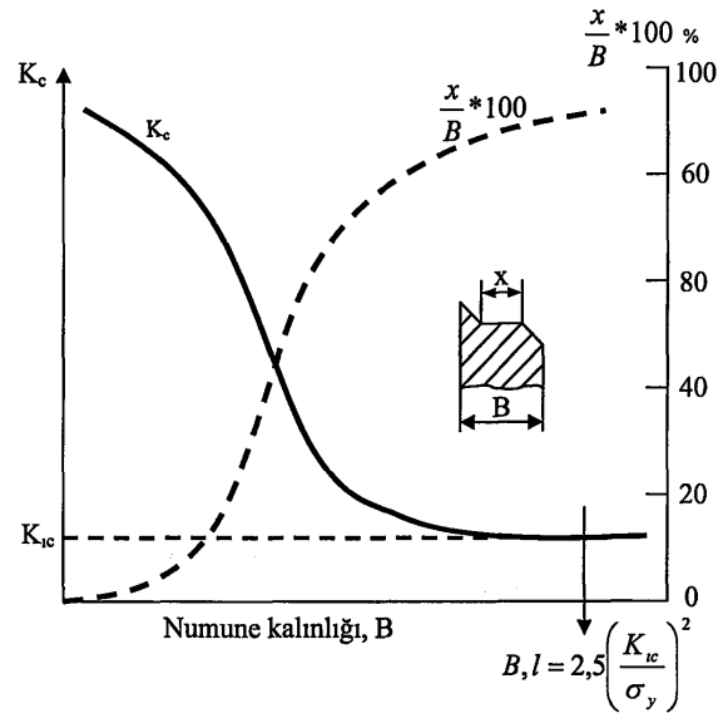

Şekil 3. Kırılma tokluğunun numune kalınlığı ile değişim grafiği (şematik)

$B, l \geq 2.5\left(\frac{K_{I C}}{\sigma_{y}}\right)^{2}$

$\mathrm{Bu}$ denklemde $K_{I C}$ yerine, ASTM E399 ile deneyden saptanan $K_{Q}$ parametresi yazıldığında;

$B, l \geq 2.5\left(\frac{K_{Q}}{\sigma_{y}}\right)^{2}$

Gevrek kırılmanın sağlanabilmesi için Denklem 4'deki eşitsizlik sağlanmalıdır. Aksi takdirde numune kalınlığı yeterli değildir ve deney tekrarlanmalıdır. Yukarıdaki eşitsizlik sağlandığında ise numune kalınlığ 1 yeterlidir ve bu durumda, $K_{Q}=K_{I C}$ olarak kabul edilir.

\subsection{Kırılma Tokluğunun Saptanmasında Kullanilan Yöntem}

$\mathrm{Bu}$ çalışmada kullanılan yöntem, HMK kafes yapısına sahip ferritik çeliklerin kırılma tokluğunun saptanması için geliştirilmiştir. $\mathrm{Bu}$ yönteme göre, bir çatlağın uç kısmında dış gerilim etkisiyle oluşan plastik deformasyonun, termoaktivasyon enerjisi ile ilişkisini göz önünde tutularak, bir hipotez ortaya atılmıştır. Bununla birlikte bu hipotezde, kırılma mikro mekanizması olarak, $K_{\mu}$ mikro mekanizması kabul edilmiştir. $\mathrm{Bu}$ hipotez uyarınca, kırılma tokluğu $\left(K_{I C}\right)$ için aşağıdaki denklem yazılmıştır (Said, 2006; Said ve Tasgetiren, 2004; Said ve Taşgetiren, 2000; Saidov, 1986, 1987, 1990, 1997; Saidov ve Seleznyova, 1997; Sa1d ve Talas, 2004).

$K_{I C}=K_{I C}^{0} e^{\alpha m T}$
$K_{\mu} \quad$ kırılma modelinin çatlak ilerleme mekanizmasında; Ana çatlak ucundan belirli bir mesafede $\left(\rho_{c}\right)$ diş kuvvet sonucu oluşan kritik gerilim $\left(\sigma_{c}\right)$ etkisiyle bir mikro çatlak meydana gelir ve bu mikro çatlak, ana çatlağa doğru hareket eder ve ana çatlak ile birleşir (aynı işlem defalarca tekrar etmektedir). $\mathrm{Bu}$ kırılma mekanizmasının matematiksel ifadesi, aşağıdaki denklemde verilmiştir (Krasovs'kyi, 2006; Krasowsky, 1980; Krasowsky vd., 1983).

$\left(\frac{K_{I C}}{K_{\mu}}\right)=\left(\frac{\sigma_{c}}{\sigma_{y}}\right)^{\frac{(1-n)}{2 n}}$

$K_{\mu}=\sigma_{c} \sqrt{\pi \rho_{c}}$

$\mathrm{Bu}$ çalışmada kullanılan yöntem temelinde, malzemenin kırılma tokluğunun $\left(K_{I C}\right)$, içyapı, deformasyon hızı, sıcaklık ve mekanik özellikler ile ilişkisi aşağıdaki denklem ile ifade edilmektedir (Said ve Aytekin, 2013; Said ve Tasgetiren, 2004; Said ve Taşgetiren, 2000; Saidov, 1987, 1990, 1997; Saidov ve Seleznyova, 1997).

$K_{I C}=A \sqrt{\pi d}\left(\frac{A}{\sigma_{y}^{*}}\right)^{\frac{\varkappa^{*}}{T^{*}} T}$

$\mathrm{Bu}$ denkleme bakıldığında, kırılma tokluğunun saptanabilmesi için malzemenin geleneksel mekanik özellikleri ve iç yapıdan elde edilen ortalama tane çapı yeterlidir.

\subsection{Akma Dayanımının Sıcaklıkla İlişkisi}

\subsubsection{Makhutov Yaklaşımı}

Makhutov'un yaklaşımı, deneysel (ampirik) olarak geliştirilmiştir. Bu yaklaşıma göre, akma gerilimin sıcaklıkla değişimi, çekme deneyinden elde edilen akma dayanımı $\left(\sigma_{y 0}\right)$ sonuçları (oda sicaklığında) ile elde edilebilmektedir. Bunun için, aşağıdaki denklem kullanılır (Serensen ve Makhutov, 1971).

$\sigma_{y(T)}=\sigma_{y 0} \exp \left[\beta_{y}\left(\frac{1}{T}-\frac{1}{T_{0}}\right)\right]$

Çekme deneyinden elde edilen akma dayanımı $\sigma_{y 0}$ ile Denklem 9'da yer alan $\beta_{y}$ parametresi arasında ilişsi Şekil 4'de verilmiştir. 


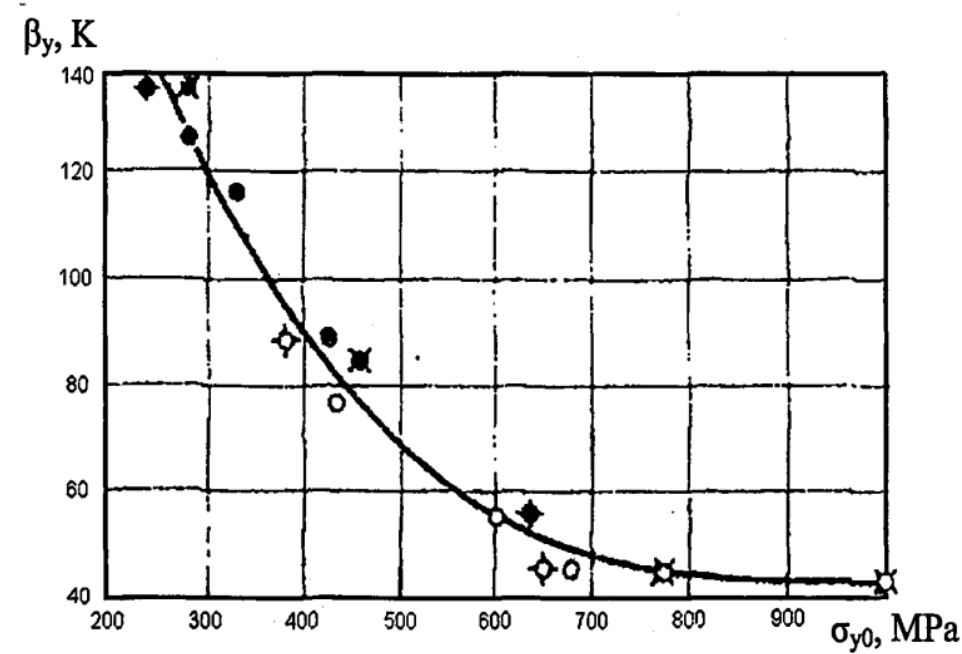

Şekil 4. $\beta_{y}$ ile $\sigma_{y 0}$ arasındaki ilişkiyi gösteren grafik (Serensen ve Makhutov, 1971)

$\beta_{y}$ parametresi, yukarıdaki grafik üzerinden hesaplanır. Bu grafik üzerindeki semboller, farklı malzemeleri ifade etmektedir.

\subsubsection{Yaroshevich Yaklaşımı}

Yaroshevich'in yaklaşımı, teorik temellere dayandırılmıştır. Bu yaklaşımda, 1970'li yıllarda "dislokasyonların çiftli eğilerek hareketi modeli" temelinde, akma geriliminin sicaklik ve deformasyon hızı ile ilişkisi için aşağıdaki denklem elde edilmiştir (Yaroshevich ve Ryvkina, 1970).

$\sigma_{y(T)}=\sigma_{0}+A e^{(-\alpha T)}$

Yukarıdaki denklemin grafiksel ifadesi Șekil 5'de verilmiştir.

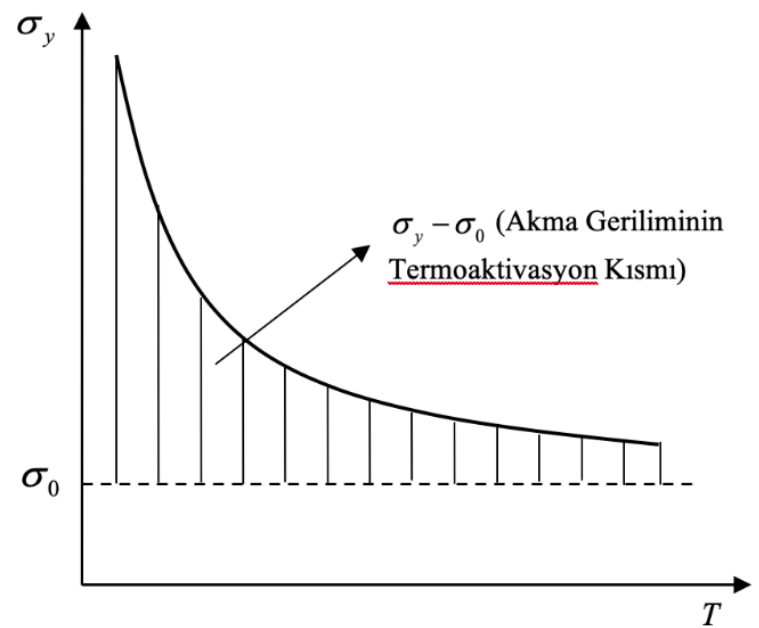

Şekil 5. Akma geriliminin atermik ve termoaktivasyon kısmı

Şekil 5'den görüldüğü üzere, akma gerilimin sıcaklıkla değişim grafiği iki kısımdan oluşmaktadır. Bunlar; 1) akma geriliminin atermik ( $\sigma_{0}$ ile ifade edilen), yani sıcaklığa bağlı olmayan ve 2) termoaktivasyon, yani sicaklığa bağlı kısmıdır.

Denklem 10'da bazı değişiklikler yapıldığında aşağıdaki denklem elde edilir.

$\ln \left(\sigma_{y}-\sigma_{0}\right)=\ln A-\alpha T$

Yukarıdaki denkleme yakından bakıldığında, yarı logaritma $\ln \left(\sigma_{y}-\sigma_{0}\right)-T$ koordinat sisteminde doğru çizgiyi ifade ettiği görülebilir. Bu denklem uyarınca, çeşitli deformasyon hızlarında akma dayanımının sıcaklıkla değişimi, Şekil 6'da verilmiştir.

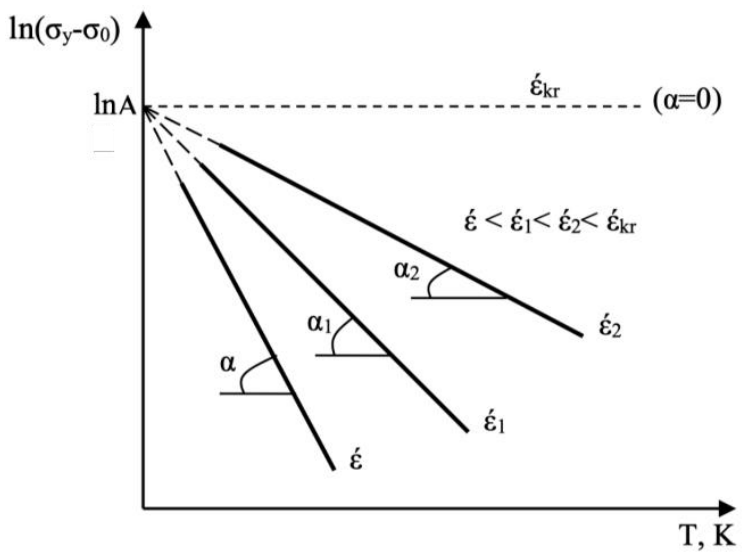

Şekil 6. Çeşitli deformasyon hızlarında akma dayanımının sıcaklıkla değişimi

Şekil 6'ya bakıldığında, deformasyon hızının artmasına bağlı olarak malzemenin akma geriliminin arttı̆g deformasyon hızına hassasiyetinin (sıcaklığa göre) zayıfladığ1 görülmektedir. $\dot{\varepsilon}=\dot{\varepsilon}_{k r} \quad$ olduğunda (yani $\quad \alpha=0$ olduğunda) akma geriliminin deformasyon hizına hassasiyeti yoktur. 


\section{5. Önerilen Yaklaşımın Temelleri}

Kırılma tokluğunun sıcaklıkla ilişkisinin Denklem 8 'e göre saptanabilmesi için Denklem 10'da yer alan $A$ parametresinin saptanmasi gerekir. Aytekin'in çalışmasında, bu parametre, çekme testi verileri (77 ile $293 \mathrm{~K}$ arasında yapılan çekme testi verileri) kullanılarak, MATLAB-CFT (MATLAB programının Curve Fitting Toolbox'1 - Eğri Uydurma Araç Kutusu) yardımıyla saptanmıştır (Aytekin, 2009).

$\mathrm{Bu}$ çalışmada, ilgili parametrenin $(A)$ saptanmasında yeni bir yaklaşım önerilmiştir. $\mathrm{Bu}$ yaklaşıma göre sadece oda sıcaklığında elde edilmiş olan akma dayanımı verisi yeterlidir. $\mathrm{Bu}$ yöntem adım adım aşağıda özetlenmiştir.

İlk olarak, Denklem 9 kullanılarak akma dayanımının sıcaklıkla değişimi elde edilir. Bunun için malzemenin oda sıcaklığındaki akma dayanımı ile Şekil 4'den $\beta_{y}$ parametresi saptanır. Sonra ise Denklem 9 kullanılarak (MATLABCFT ile) Denklem 10 saptanır. Ancak, Denklem 9 ile Denklem 10 birbirlerinden matematiksel olarak (özellikle düşük sıcaklıklarda akma dayanımının sayısal değeri olarak) oldukça farklıdır. Örneğin; Denklem 9'da $0 \mathrm{~K}$ sıcaklığında sonuç tanımsızdır. Dolayısıla, Denklem 9 ile Denklem 10'un nispeten uyumlu olduğu sicaklık aralığı belirlenmelidir. Özellikle de başlangıç sıcaklığı belirlenmelidir. Bitiş sıcaklığı, deneyin yapıldığ 1 sıcaklık, yani $293 \mathrm{~K}$ olmalıdır. Başlangıç sıcaklığı için ise, aşağıdaki denklem önerilmiştir.

$T_{\text {baṣ. }}=\beta_{y}+25$

Yukarıdaki denkleme göre, iki denklem (Denklem 9 ve 10) arasındaki tutarlı sicaklık aralığının başlangıç noktası olarak bir malzeme için anlamlı en düşük sicaklık değeri olan $\beta_{y}$ değerinin $25 \mathrm{~K}$ üstü dikkate alınmalıdır. $\mathrm{Bu}$ kabul, bulgular kısmında elde edilen $\mathrm{R}^{2}$ değerleri ile desteklenmektedir. Şekil 4'den saptanan $\beta_{y}$ parametresi ile Denklem 12 yardımıyla saptanan

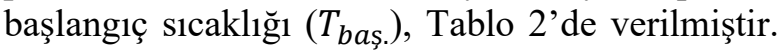
Böylece sıcaklık aralığ 1 olarak, $T_{b a s ̧ . ~}$ ile $293 \mathrm{~K}$ belirlenmiştir.

Tablo 2. $\beta_{y}$ ve $T_{b a s ̧ . ~}$ parametrelerinin sayısal değerleri

\begin{tabular}{ccc}
\hline \multirow{2}{*}{ Çelik No } & $\boldsymbol{\beta}_{\boldsymbol{y}}$ & $\boldsymbol{K}$ \\
\cline { 2 - 4 } & & $\boldsymbol{T}_{\boldsymbol{b a s .}}$ \\
\hline 1 & 56 & 81 \\
2 & 65 & 90 \\
3 & 128 & 153 \\
4 & 109 & 134 \\
5 & 90 & 115 \\
\hline
\end{tabular}

Tablo 2'de, akma dayanımının sicaklıkla değişiminin Denklem 9'a göre saptanmasında kullanılan $\beta_{y}$ parametresinin, akma dayanımının azalmasına bağlı olarak arttığı (Şekil 4'den de görüldüğü üzere) görülmektedir.

\subsection{Mekanik Test ve Tane Çapı Verileri}

Aytekin'in çalışmasında, incelenen çelikler üzerinde çekme deneyleri ve ortalama tane çapı analizi yapılmıştır. $\mathrm{Bu}$ parametrelerden, oda sıcaklığındaki akma dayanımı $\left(\sigma_{y 0}\right)$, pekleşme katsay1s1 $\left(n^{293}\right)$ ve saptanan baz1 parametreler $\left(S_{\text {kop. }}, T_{\text {s.p. }}\right)$ ile ortalama tane çapı $(d)$ değerleri, Tablo 3'de verilmiştir (Aytekin, 2009).

Tablo 3. İncelenen çeliklerin mekanik test ve ortalama tane çapı verileri (Aytekin, 2009).

\begin{tabular}{|c|c|c|c|c|c|}
\hline \multirow{2}{*}{ Çelik No } & $\sigma_{y 0}$ & $S_{\text {kop }}$ & \multirow{2}{*}{$\begin{array}{c}T_{\text {s.p. }} \\
K\end{array}$} & \multirow{2}{*}{$n^{293}$} & \multirow{2}{*}{$\begin{array}{c}d * 10^{6} \\
m\end{array}$} \\
\hline & \multicolumn{2}{|c|}{$M P a$} & & & \\
\hline 1 & 582 & 1148 & 60 & 0.1122 & 105 \\
\hline 2 & 510 & 995 & 74 & 0.1428 & 63 \\
\hline 3 & 285 & 657 & 93 & 0.1983 & 63 \\
\hline 4 & 339 & 819 & 72 & 0.1738 & 22,4 \\
\hline 5 & 401 & 914 & 76 & 0.1288 & 22,4 \\
\hline
\end{tabular}


Tablo 3'den görüldüğü üzere, çeliklerin, akma dayanımına göre, düşük ve orta dayanımlı çelik sınıfinda olduğu söylenebilir. Aytekin'in çalışmasında, $S_{\text {kop }}$. ve $T_{\text {s.p. }}$ parametreleri, çekme deneyi verileri (77 ile $293 K$ arasındaki test verileri) kullanılarak, MATLAB-CFT yardımıyla saptanmıştır. $\mathrm{Bu}$ parametrelerin güvenilirliği ve doğruluğu, ilgili parametrelerin saptanmasında doğrudan çekme testi verileri kullanıldığından, oldukça yüksektir (Aytekin, 2009).

Aytekin'in çalışmasında, ASTM E399 standardı uyarınca üç farklı $(77,123$ ve $173 \mathrm{~K})$ sıcaklıkta deney yapılmıştır. CT1T numunesi üzerinde yapılan deneylerde, ilk olarak çentikli numunede yorulma çatlağı oluşturulmuş, daha sonra numune kırılana kadar yüklenerek $P-V$ grafiği elde edilmiştir. $\mathrm{Bu}$ grafik üzerinden belirlenen kuvvet değeri ile numune kırıldıktan sonra ölçülen çatlak uzunluğu, Denklem 1'de yerine yazılarak kırılma tokluğu saptanmıştır. Bu denklemde yer alan düzeltme parametresinin denklemi (polinom) ilgili çalışmada bulunmaktadır. Elde edilen kırılma tokluğu değerleri, Tablo 4'de verilmiştir (Aytekin, 2009).

Tablo 4. ASTM E399 standardına göre saptanan kırılma tokluğu verileri (Aytekin, 2009).

\begin{tabular}{|c|c|c|c|c|}
\hline \multirow{3}{*}{\multicolumn{2}{|c|}{ Deney Sıcaklığı, $K$}} & \multirow{2}{*}{\multicolumn{3}{|c|}{ Kırılma Tokluğu $\left(K_{I C}\right), M P a \sqrt{m}$}} \\
\hline & & & & \\
\hline & & 77 & 123 & 173 \\
\hline \multirow{15}{*}{ Çelik No } & \multirow{3}{*}{1} & 58 & 83 & 60 \\
\hline & & 56 & 58 & 93 \\
\hline & & 54 & 70 & 75 \\
\hline & \multirow{3}{*}{2} & 49 & 64 & 49 \\
\hline & & 49 & 62 & 54 \\
\hline & & 47 & 73 & 58 \\
\hline & \multirow{3}{*}{3} & 38 & 40 & 47 \\
\hline & & 36 & 39 & 45 \\
\hline & & 34 & 45 & 74 \\
\hline & \multirow{3}{*}{4} & 42 & 55 & 79 \\
\hline & & 39 & 38 & 85 \\
\hline & & 40 & 63 & 67 \\
\hline & \multirow{3}{*}{5} & 41 & 53 & 45 \\
\hline & & 41 & 62 & 60 \\
\hline & & 39 & 49 & 64 \\
\hline
\end{tabular}

Tablo 4'e bakıldığında, deney verilerine göre, en düşük sıcaklıkta $(77 \mathrm{~K})$ saptanan kırılma tokluğu sonuçları, 1 ve 2 nolu çelikte biraz yüksek olmakla birlikte, birbirlerine oldukça yakındır. Bunun sebebi, düşük sıcaklıklarda, ferritik çeliklerin, doğasal olarak benzer kırılma tokluğu değerlerine sahip olmasıdır. Kırılma tokluğunun $293 K$ sicaklığında (oda sicaklığı) saptanmamış olmasının nedeni ise 1 inçlik numune kalınlığının, lineer elastik kırılma mekaniği açısından (ASTM E399), bu sıcaklık için yeterli olmamasıdır (Aytekin, 2009).

\section{Bulgular}

\subsection{Akma Dayanımı Analizi}

İncelenen çeliklerin akma dayanımının sıcaklıkla değişim grafikleri ve Denklem 9 verileri kullanılarak saptanan parametrelerin (Denklem 10'da yer alan) sayısal değerleri aşağıdaki grafiklerde verilmiştir.
Şekil 7'ye bakıldı̆̆ında, akma dayanımının sıcaklıkla değişiminin saptanmasında kullanılan Denklem 9 ve Denklem 10'un, bu çalışmada önerilen sıcaklık aralığında ( $T_{b a s ̧ . ~}$ ile $293 \mathrm{~K}$ ), birbirleriyle oldukça uyumlu olduğu görülmektedir. Grafiklerde yer alan ve grafiği ikiye bölen çizgiler, $T_{\text {baș. }}$ sıcaklığını ifade etmektedir. Denklem 10'da yer alan parametrelerin saptanmasinda, bu sicaklığın $\left(T_{\text {baş. }}\right)$ sol tarafındaki değerler (Denklem 9 ile saptanan) dışlanarak (kırmızı noktalar), ilgili sıcaklığın $\left(T_{b a s ̧ .}\right)$ sağ tarafındaki değerler (siyah noktalar) dikkate alınmıştır. Böylece iki denklem arasındaki uyumsuz kısım atılmıştır. Denklem 10 'da yer alan parametreler, MATLAB programının eğri uydurma araç kutusu (MATLAB-CFT) yardımıla, Denklem 9 kullanılarak hesaplanan verilere Denklem 10'un uydurulması ile saptanmıştır. $\mathrm{Bu}$ parametreler, Tablo 5'de verilmiştir. 

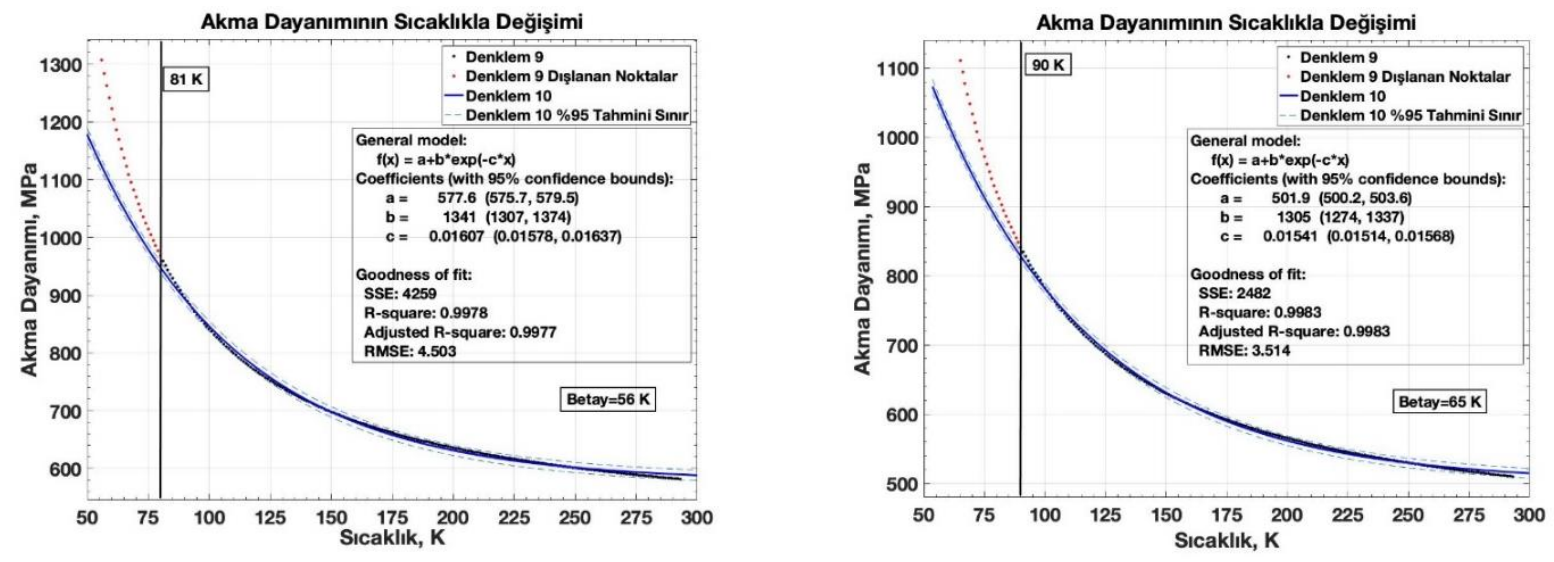

1 nolu çelik

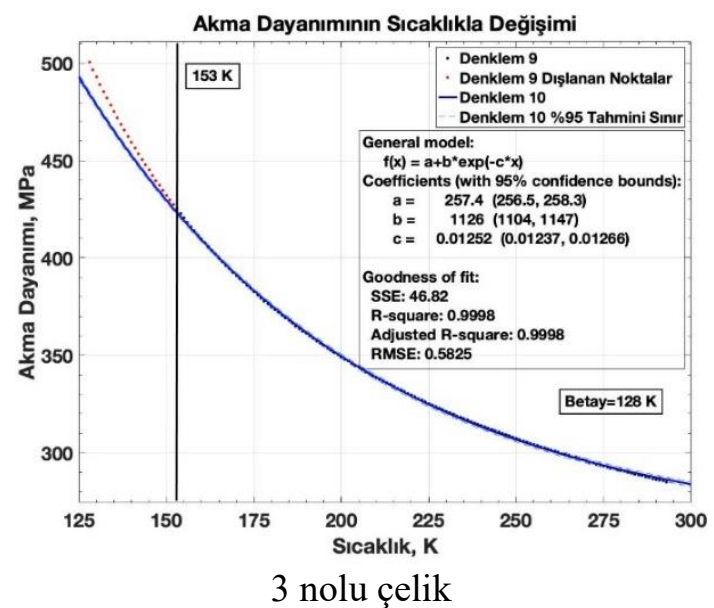

2 nolu çelik

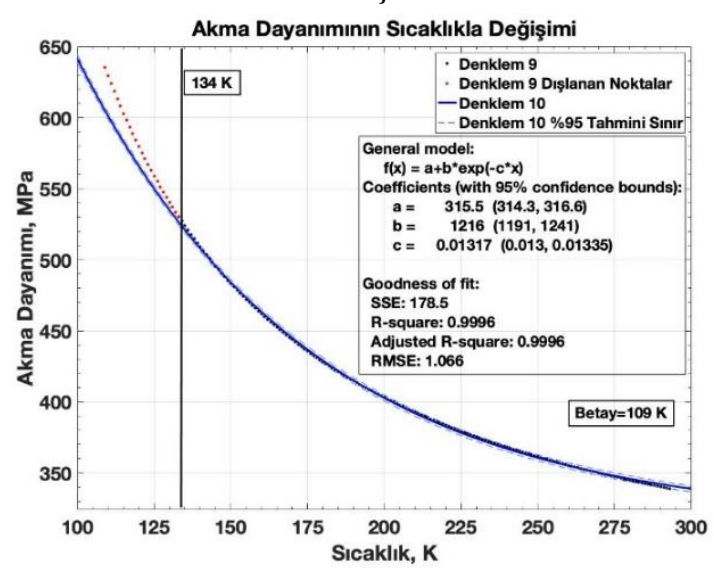

4 nolu çelik

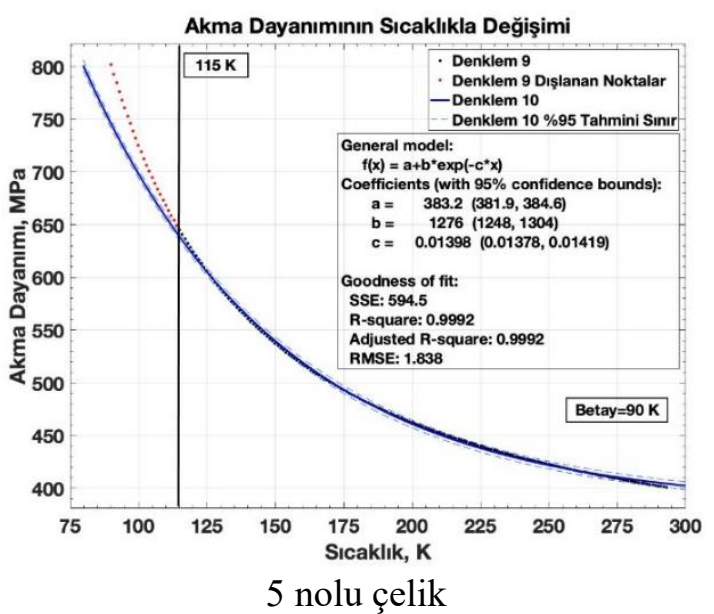

Şekil 7. Akma dayanımının sıcaklıkla değişim grafikleri ve saptanan parametreler.

Tablo 5. Denklem 10'da yer alan parametrelerin sayısal değerleri

\begin{tabular}{ccccc}
\hline \multirow{2}{*}{ Çelik No } & $\mathbf{A}$ & $\boldsymbol{\sigma}_{\mathbf{0}}$ & $\boldsymbol{\alpha}$ \\
\cline { 2 - 4 } & & $\boldsymbol{M P a}$ & & $\boldsymbol{K}^{-\mathbf{1}}$ \\
\hline 1 & 1341 & 577.6 & 0.01607 \\
3 & 1305 & 501.9 & 0.01541 \\
4 & 1126 & 257.4 & 0.01252 \\
5 & 1216 & 315.5 & 0.01317 \\
\hline
\end{tabular}


Tablo 5'de verilmiş olan parametreler (ve Denklem 10'da yer alan), akma dayanımının sicaklıkla değişimini ifade etmektedir. Bu tabloya bakıldığında, ilgili parametrelerin sayısal değerlerinin, oda sıcaklığında deneysel olarak saptanan akma dayanımı ile yakından ilgili olduğu görülmektedir.
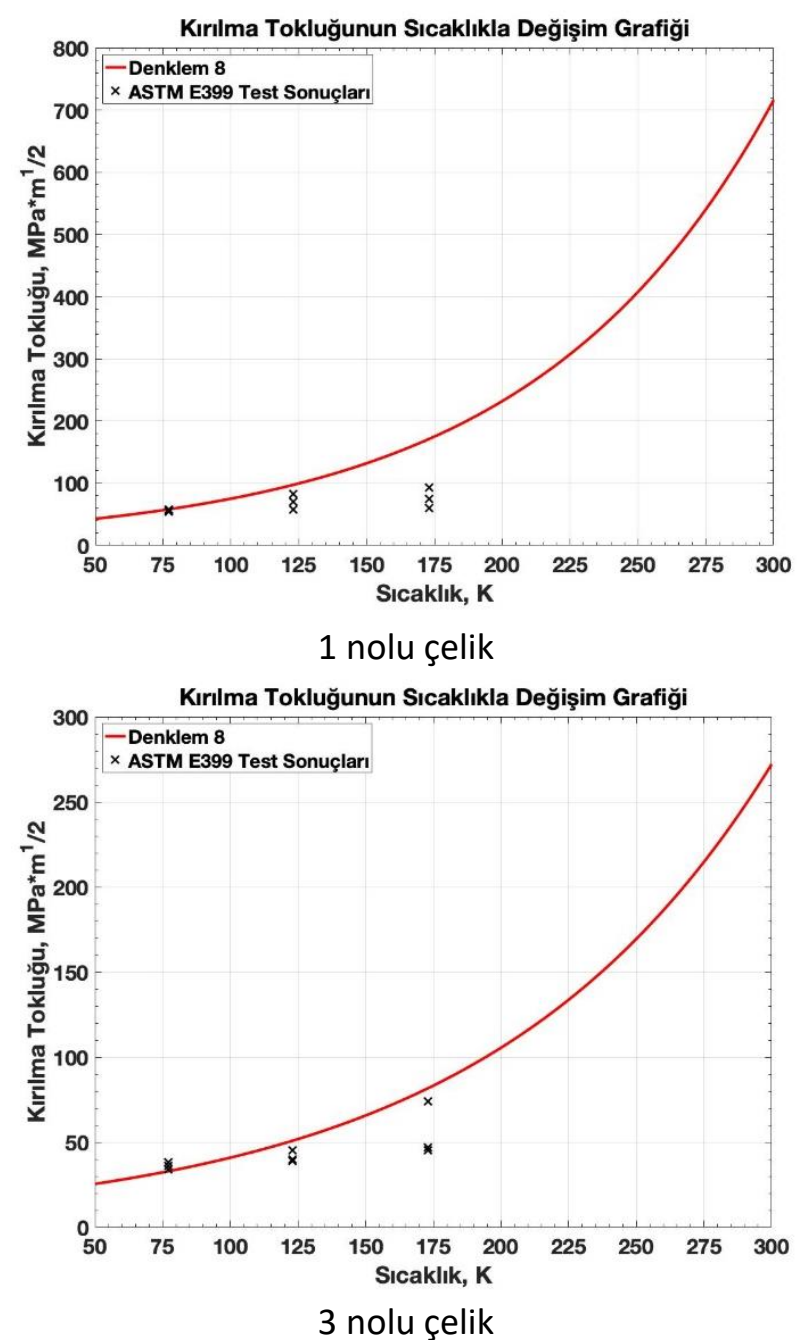

\subsection{Kırılma Tokluğu Analizi}

İncelenen çeliklerin kırılma tokluğunun sıcaklıkla değişim grafikleri (bu çalışmada saptanan) ve ASTM E399 standardına göre saptanan kırılma tokluğu verileri (Aytekin'in çalışmasından alınan (Aytekin, 2009)), Şekil 8'de verilmiştir.
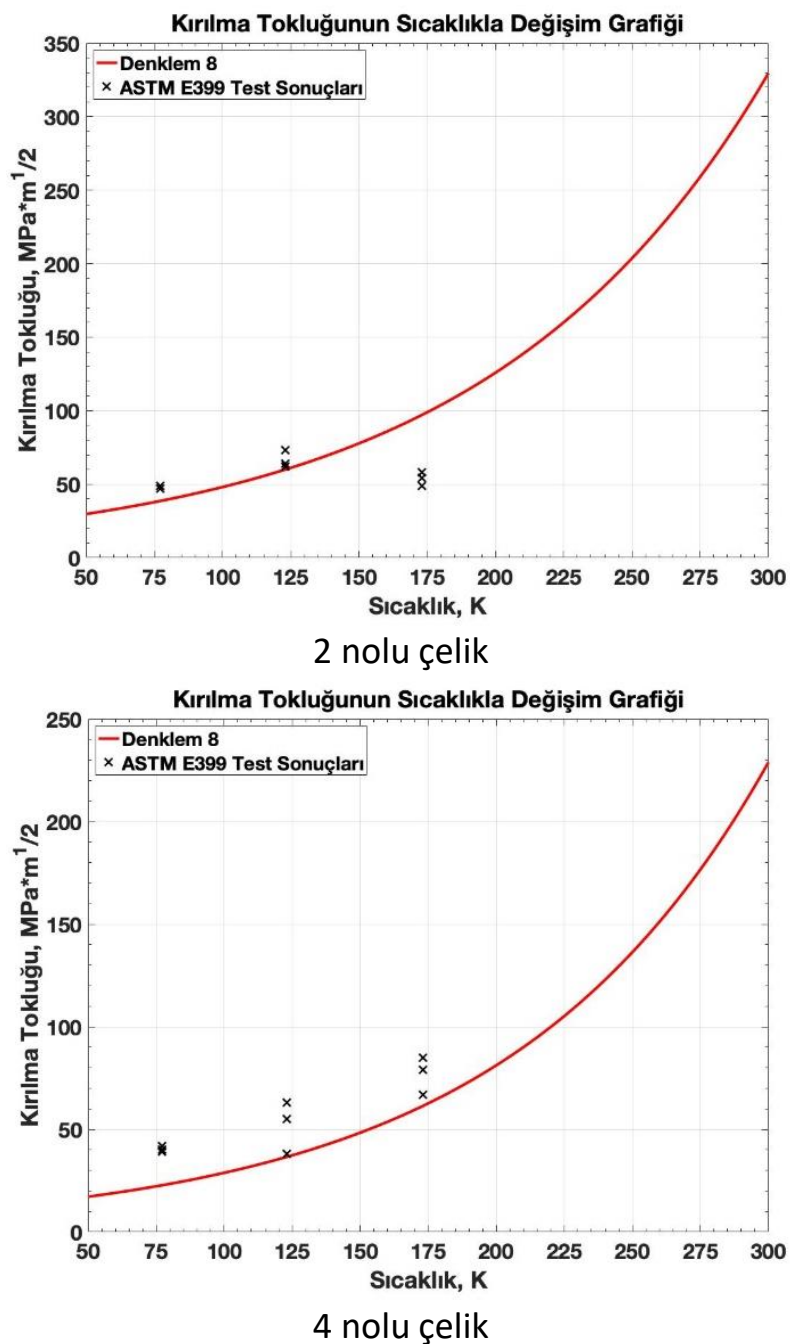

4 nolu çelik

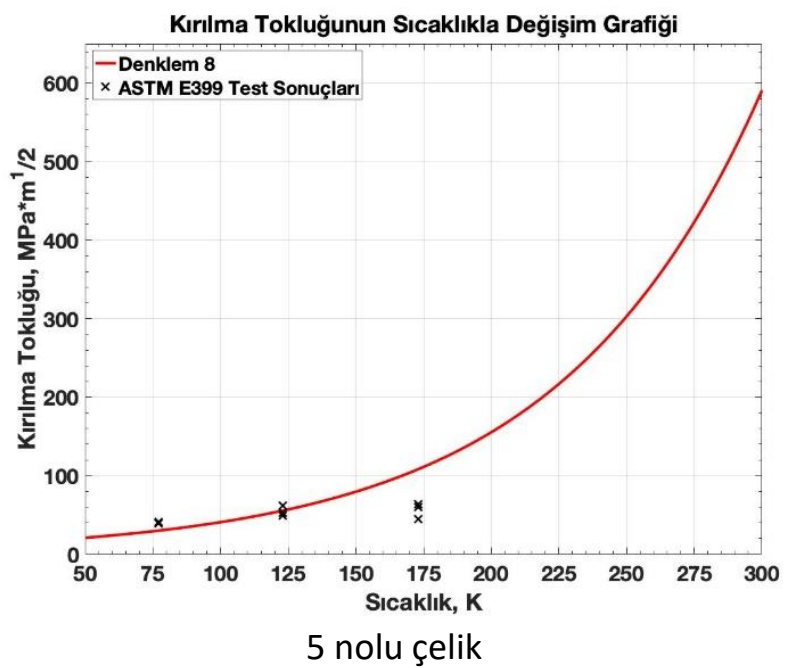

Şekil 8. Kırılma tokluğunun sıcaklıkla değişim grafikleri ve ASTM E399 standardına göre saptanan kırılma tokluğu verileri. 
Şekil 8'e bakıldığında, düşük sıcaklıklarda, tüm çelikler için (4 nolu çelik hariç) ASTM E399 ile saptanan kırılma tokluğu deney sonuçlarının, önerilen yaklaşım kullanılarak Denklem 8'e göre saptanan kırılma tokluğu değerleri ile oldukça uyumlu olduğu söylenebilir. Bu çelikler için yüksek sıcaklıklardaki uyumsuzluğun nedeni ise ferritik çeliklerin sünek-gevrek geçiş doğasından kaynaklanan kırılma tokluğu değerlerindeki tutarsızlıklar olabilir. 4 nolu çelikte ise her iki yönteme göre saptanan kırılma tokluğu değerlerinin, yüksek sıcaklıklarda nispeten daha uyumlu olduğu görülmektedir. Genel olarak, kırılma tokluğunun saptanmasında Denklem 8'in güvenilir olduğu söylenebilir. Kırılma tokluğunun Denklem 8'e göre saptanmasında kullanılan Denklem 10'da yer alan parametrelerin, yeni yaklaşım ile hassas bir şekilde saptanmış olmasının, buna olumlu katkısı açıktır. $\mathrm{Bu}$ sebeple, Denklem 10'da yer alan parametrelerin saptanmasında, geliştirilen yeni yaklaşım oldukça anlamlidir.

\section{Sonuç ve Değerlendirme}

$\mathrm{Bu}$ çalışmada elde edilen sonuçlar aşağıda maddeler halinde sıralanmıştır.
- Yeni yaklaşım ile akma dayanımının sıcaklıkla değişiminin saptanabilmesi için sadece oda sicaklığında yapılan çekme testi verileri yeterlidir.

- Genel olarak, ASTM E399 standardına göre saptanan kırılma tokluğu test sonuçları ile yeni yaklaşım yardımıyla belirlenen kırılma tokluğu sonuçları (4 nolu çelik hariç) düşük sıcaklıklarda oldukça uyumludur.

- Ferritik çeliklerin kırılma tokluğunun tahmininde, bu çalışmada geliştirilen yaklaşımın, özellikle düşük sıcaklıklarda, güvenilir olduğu söylenebilir.

Sonuç olarak, bu çalışmada incelenen yeni yaklaşım, ferritik çeliklerin akma dayanımının sıcaklıkla değişiminin ve dolayısıyla da kırılma tokluğunun saptanmasında, alternatif bir yöntem olarak önerilebilir.

\section{Teşekkür}

$\mathrm{Bu}$ çalışma, 17.TEKNOLOJİ.02 proje numarası ve "Ferritik Çeliklerde Kırllma Tokluğunun Saptanmasında Farklı Bir Yaklaşım" ismiyle Afyon Kocatepe Üniversitesi Bilimsel Araştırma Projeleri Koordinasyonu (BAPK) tarafindan desteklenmiştir.

\section{Simgeler}

\begin{tabular}{|c|c|}
\hline$A$ & Akma geriliminin $T=0 \mathrm{~K}$ 'deki etkili değeri, $M P a$ \\
\hline$\alpha$ & $\begin{array}{l}\text { Akma geriliminin belirli bir deformasyon hızında sıcaklı̆ga hassasiyetini ifade eden bir } \\
\text { parametre, } K^{-1}\end{array}$ \\
\hline$b$ & ASTM E399 standardına göre CT (kompakt çekme) numunesinin genişliği, mm \\
\hline$B, l$ & ASTM E399 standardına göre numune kalınlığı, $\mathrm{mm}$ \\
\hline$\beta_{y}$ & Akma dayanımının sıcaklıkla değişimi ifade eden bir parametre, $K$ \\
\hline$d$ & Ortalama tane çapı, $m$ \\
\hline$\dot{\varepsilon}$ & Deformasyon hizı, $s n^{-1}$ \\
\hline$\dot{\varepsilon}_{k r}$ & Kritik deformasyon hizl, $s n^{-1}$ \\
\hline $\mathcal{H}^{*}$ & $\mathcal{\varkappa}^{*}=\frac{1-n^{*}}{2 n^{*}}$ denklemine uygun sayısal değer \\
\hline$K_{C}$ & Kritik gerilim şiddet katsayısı, $M P a \sqrt{m}$ \\
\hline$K_{C(\max )}$ & Kritik gerilim şiddet katsayısının maksimum değeri, $M P a \sqrt{m}$ \\
\hline$K_{Q}$ & ASTM E399 standardına göre $P_{Q}$ kuvvetine uygun kirllma tokluğu, MPa $\sqrt{m}$ \\
\hline$K_{I C}$ & Malzemenin kirılma tokluğu, $M P a \sqrt{m}$ \\
\hline$K_{I C}^{0}$ & Kırılma tokluğunun $T=0 K^{\prime}$ deki değeri, $M P a \sqrt{m}$ \\
\hline$K_{J C}$ & J-integral yöntemi ile elde edilen kırılma tokluğu, MPa $\sqrt{m}$ \\
\hline$K_{\mu}$ & $\begin{array}{l}\text { Kırılma mikro mekanizmasına uygun kırılma tokluğu değeri (sıcaklık ve deformasyon } \\
\text { hızına bağlı değildir), MPa } \sqrt{m}\end{array}$ \\
\hline$\ell_{0}$ & ASTM E399 standardına göre CT numunesinde çatlak uzunluğu, $\mathrm{mm}$ \\
\hline$m$ & Kırılma tokluğunun sicakliğa hassasiyetini ifade eden katsayl \\
\hline$n$ & Malzemenin pekleşme katsayısı \\
\hline$n^{*}$ & Sünek - gevrek geçiş sıcakllğına uygun pekleşme katsayısı \\
\hline$n^{293}$ & $T=293$ K sicaklığa uygun pekleşme katsayısı değeri \\
\hline$P$ & Kuvvet değeri, $N$ \\
\hline
\end{tabular}




\begin{tabular}{|c|c|}
\hline$P_{Q}$ & Kuvvet çatlak açılma diyagramında maksimum kuvvet, $N$ \\
\hline$\rho_{c}$ & Çatlak ucundan belirli bir mesafe, $m$ \\
\hline$S_{k o p}$ & $\begin{array}{l}\sigma_{y}=\sigma_{\max }=S_{k}, \psi=0 \text { şartına uygun malzemenin kopmaya karşı direnci (sadece } \\
\text { malzemenin tane boyutuna bağlldır), } \mathrm{MPa}\end{array}$ \\
\hline$\sigma_{0}$ & Akma geriliminin sıcaklıkla bağımsız (atermik) değeri, $M P a$ \\
\hline$\sigma_{c}$ & $\begin{array}{l}\text { Çatlak ucunda } \rho_{c} \text { mesafede meydana gelen kritik gerilim, (sıcaklık ve deformasyon hizına } \\
\text { bağll değildir) MPa }\end{array}$ \\
\hline$\sigma_{y}^{*}$ & Sünek - gevrek geçiş sıcaklı̆̆ına uygun akma dayanımı, $M P a$ \\
\hline$\sigma_{y}$ & Akma mukavemeti, $\mathrm{MPa}$ \\
\hline$\sigma_{y(T)}$ & Herhangi bir deney sicaklığındaki akma gerilimi, $M P a$ \\
\hline$\sigma_{y 0}$ & Akma geriliminin $T_{0}=293 \mathrm{~K}$ 'deki değeri, $\mathrm{MPa}$ \\
\hline$t$ & ASTM E399 standardına göre CT numunesinin kalınlığl, $\mathrm{mm}$ \\
\hline$T$ & Mutlak sicaklık, $K$ \\
\hline$T_{\text {baş. }}$ & $\begin{array}{l}\text { Akma dayanımının sıcaklıkla değişiminin kararlı olduğu slcaklık aralı̆̆ının başlangıç } \\
\text { slcaklığl, K }\end{array}$ \\
\hline$T_{0}$ & Oda sicakliğı, $K$ \\
\hline$T_{o}$ & ASTM E1921 standardına göre referans sıcaklığı, $K$ \\
\hline$T^{*}$ & Sünek - gevrek geçiş slcaklı̆̆ \\
\hline$T_{\text {s.p. }}$ & Sifir plastiklik sıcaklı̆̆ı, $K$ \\
\hline$Y$ & $\begin{array}{l}\text { Malzemenin boyut faktörü, çatlağın dış kuvvete göre yerleşim durumunu ifade eden bir } \\
\text { parametre }\end{array}$ \\
\hline
\end{tabular}

\section{Kaynaklar}

ASTM E1921-18, 2018. Standard Test Method for Determination of Reference Temperature, To, for Ferritic Steels in the Transition Range, in: ASTM Volume 03.01 Metals - Mechanical Testing; Elevated and Low-Temperature Tests; Metallography: West Conshohocken, PA: ASTM International.

ASTM E399-17, 2017. Standard Test Method for Linear-Elastic Plane-Strain Fracture Toughness KIc of Metallic Materials, in: ASTM Volume 03.01 Metals - Mechanical Testing; Elevated and Low-Temperature Tests; Metallography: West Conshohocken, PA: ASTM International.

Aytekin, H., 2005. Yapı Çeliklerinin Kırılma Tokluğu Üzerine Bir Çalışma. Yüksek Lisans Tezi, Afyon Kocatepe Üniversitesi, Fen Bilimleri Enstitüsü, Afyonkarahisar.

Aytekin, H., 2009. Yapı Çeliklerinin Kırılma Tokluğunun Saptanmasında Yeni Bir Yöntemin Geliştirilmesi. Doktora Tezi, Afyon Kocatepe Üniversitesi, Fen Bilimleri Enstitüsü, Afyonkarahisar.

Aytekin, H., 2014. A Study on the ASTM E1921 Standard in Determining the Fracture Toughness of Ferritic Steels. Fatigue \& Fracture of Engineering Materials \& Structures, 37(8), 920-927.

Berejnoi, C. ve Ipiña, J.E.P., 2016. Fracture Toughness of Ferritic Steels in the Ductile-to-Brittle
Transition Region, in: Fracture Mechanics Properties, Patterns and Behaviours: InTech, pp. 83-101.

Bouchard, R., Shen, G. ve Tyson, W.R., 2008. Fracture Toughness Variability of Structural Steel. Engineering Fracture Mechanics, 75(12), 37353742 .

Broek, D., 1982. Elementary Engineering Fracture Mechanics: Springer Netherlands, $469 \mathrm{p}$.

Burdekin, F.M. ve Stone, D.E.W., 1966. The Crack Opening Displacement Approach to Fracture Mechanics in Yielding Materials. The Journal of Strain Analysis for Engineering Design, 1(2), 145-153.

EricksonKirk, M. ve EricksonKirk, M., 2006. An Upper-Shelf Fracture Toughness Master Curve for Ferritic Steels. International Journal of Pressure Vessels and Piping, 83(8), 571-583.

Gdoutos, E.E., 1993. J-integral and Crack Opening Displacement Fracture Criteria, in: Fracture Mechanics: pp. 153-193.

IAEA, 2009. Master Curve Approach to Monitor Fracture Toughness of Reactor Pressure Vessels in Nuclear Power Plants: International Atomic Energy Agency, ISBN 978-92-0-111009-1, Vienna, $167 \mathrm{p}$.

Krasovs'kyi, A.Y., 2006. On the "Local Approach" to the Brittle Fracture of Structural Materials. Materials Science, 42(2), 183-188. 
Krasowsky, A.J., 1980. Brittleness of Metals at Low Temperatures: Naukova Dumka, Kyiv, (in Russian).

Krasowsky, A.J., Kashtalyan, Y.A. ve Krasiko, V.N., 1983. Brittle-to-Ductile Transition in Steels and the Critical Transition Temperature. International Journal of Fracture, 23(4), 297315 .

McCabe, D., Merkle, J. ve Wallin, K., 2000. Technical Basis for the Master Curve Concept of Fracture Toughness Evaluations in the Transition Range, Fatigue and Fracture Mechanics: 30th Volume, ASTM International, p. 21-33.

Pan, J., Chen, Z. ve Hong, Z., 2019. A Novel Method to Estimate the Fracture Toughness of Pressure Vessel Ferritic Steels in the Ductile to Brittle Transition Region Using Finite Element Analysis and Master Curve Method. International Journal of Pressure Vessels and Piping, 176, 1-11.

Planman, T., Onizawa, K., Server, W. ve Rosinski, S., 2007. IAEA Coordinated Research Project on Master Curve Approach to Monitor Fracture Toughness of RPV Steels: Applicability for Highly Embrittled Materials, ASME Pressure Vessels and Piping Division Conference, July 2007, San Antonio, Texas, p. 201-209.

Rice, J.R., 1964. A Path Independent Integral and the Approximate Analysis of Strain Concentration by Notches and Cracks. Journal of Applied Mechanics, Transactions ASME, 35(2), 379388.

Said, G., 2006. Study on ASTM E399 and ASTM E1921 Standards. Fatigue \& Fracture of Engineering Materials \& Structures, 29(8), 606614.

Said, G. ve Aytekin, H., 2013. A New Method for Determining the Fracture Toughness of Main Pipeline Steels. Fatigue \& Fracture of Engineering Materials \& Structures, 36(7), 640649.

Said, G. ve Tasgetiren, S., 2004. An Express Technique for the Determination of Static and Dynamic Fracture Toughness (KIC, Kid) of BCC Metals and Alloys. Mechanics of Materials, 36(11), 1129-1142.

Said, G. ve Taşgetiren, S., 2000. Fracture Toughness Determination of Low-Alloy Steels by Thermoactivation Energy Method. Engineering Fracture Mechanics, 67(4), 345-356.
Saidov, G.I., 1986. Theoretical-Experimental Determination of Critical Stresses in Structural Elements. Strength of Materials, 18(2), 171173.

Saidov, G.I., 1987. Thermal Activation Parameters of Deformation and the Critical Stress Intensity Factor of Low and Medium Strength Steels. Soviet Materials Science, 22(5), 495-499.

Saidov, G.I., 1990. Temperature Relationships of Static and Dynamic Crack Resistance of Low and Medium Strength Constructional Steels. Metal Science and Heat Treatment, 32(4), 299-302.

Saidov, G.I., 1997. A Thermal Activation Approach to the Crack Resistance of Steels. Fatigue \& Fracture of Engineering Materials \& Structures, 20(1), 41-47.

Saidov, G.I. ve Seleznyova, T.A., 1997. On the Fracture Toughness of Low and Medium Strength Steels (BCC Metals). Strength of Materials, 29(2), 204-207.

Sa1d, G. ve Talas, S., 2004. The Relationship Between Brittle Fracture Temperature and Stress Concentration in BCC Steels. Mechanics of Materials, 36(11), 1123-1128.

Schindler, H.-J. ve Kalkhof, D., 2015. A Closer Look at Effects of the Loading Rate on Fracture Toughness in the Ductile-to-Brittle Transition Regime of a Ferritic Steel. Journal of Testing and Evaluation, 43(3), 507-516.

Schindler, H.J., 2014. Fracture Toughness of Ferritic Steels: Lower Bounds and Their Implications on Testing and Application. Procedia Engineering, 86, 247-257.

Serensen, S. V. ve Makhutov, N.A., 1971. Resistance of Construction Elements to Brittle Failure. Strength of Materials, 3(4), 371-381.

Ulu, S., Aytekin, H. ve Said, G., 2013. An Alternative Approach to the Fracture Toughness of Dual Phase Steels. Strength of Materials, 45(5), 607618.

Yaroshevich, V.D. ve Ryvkina, D.G., 1970. On the Thermoactivation Character of Plastic Deformation of Metals. Fizika Tverdogo Tela (Solid State Physics), 12(2), 464-477, (in Russian). 